\title{
WADAH KOMUNITAS DAN REKREASI SEBAGAI RUANG KE - 3 DENGAN URBAN AKUPUNTUR METODE MENGHIDUPKAN DAN MENGEMBALIKAN CITRA PASAR BARU
}

\author{
Stephen $^{1)}$, Franky Liauw ${ }^{2)}$ \\ 1)Program Studi S1 Arsitektur, Fakultas Teknik, Universitas Tarumanagara, stephennugroho03.com \\ 2)Program Studi S1 Arsitektur, Fakultas Teknik, Universitas Tarumanagara, frankyl@ft.untar.ac.id
}

Masuk: 13-07-2020, revisi: 31-07-2020, diterima untuk diterbitkan: 23-09-2020

\begin{abstract}
Abstrak
Saat ini aktivitas Jual-beli/perdagangan sudah berkembang pesat selama beberapa dekade. Tumbuhnya mall-mall baru tersebar di seluruh Jakarta. Menjadikan Jakarta sebagai kota dengan pusat perbelanjaan terbanyak dan terbesar di dunia, dengan lebih dari 173 mall. Ditambah dengan bantuan teknologi, platform online shop memudahkan pengunjung untuk berbelanja tanpa perlu datang ke toko. Dengan bantuan alat media elektronik seperti tablet atau Smartphones. Saat ini, mall bukan hanya menjadi tempat untuk berbelanja melainkan menjadi tempat rekreasi, bersosialisasi, atau hanya sekedar untuk jalan-jalan semata. Kemajuan teknologi serta budaya manusia yang berubah, merupakan salah satu faktor yang berpengaruh terhadap dampak penurunan pengunjung di pusat perbelanjaan lama setiap tahunnya, seperti pusat perbelanjaan Pasar Baru. Re-Imagine Pasar Baru Merupakan proyek yang bertujuan sebagai motor / pengerak daerah Pasar Baru. Mengajak masyarakat dan para pedagang untuk ikut andil dalam melakukan suatu perubahan. Lewat program yang mempererat kesatuan dan persatuan guna memunculkan sikap gotong royong yang sudah hilang seiring berkembangnya zaman. Menciptakan tempat dimana warga dapat bersosialisasi dan berinteraksi, mendekatkan, saling mengenal satu sama lain dan juga sebagai sarana rekreasi warga lokal, dan proyek ini berharap dapat menghidupkan kawasan perbelanjaan Pasar Baru. Lewat metode Urban Acupunture yaitu dengan menganalisis kebutuhan, potensi, kekurangan, demografi, ekologi yang menjadi ciri khas dari kawasan Pasar Baru. Dimana dapat menghadirkan suatu program baru, dan menghasilkan perubahan skala kecil, tetapi intervensi katalitik sosial ke dalam tatanan ruang kota. Bukan hanya sekedar bentuk fisik, tetapi juga berdampak pada sosial dan budaya Kawasan Pasar Baru sendiri.
\end{abstract}

Kata kunci: Akupuntur Perkotaan; Gotong Royong; Komunitas; Pasar Baru Rekreasi

\begin{abstract}
At present the activity of buying and selling/trading has been developing rapidly for decades. The growth of new malls spread throughout Jakarta. Making Jakarta the city with the largest and most shopping center in the world, with more than 173 malls. Coupled with the help of technology, an online shop platform has emerged that makes it easy for visitors to shop without having to come to the store. With the help of electronic media tools such as tablets or Smartphones. Nowadays, malls are not only a place to shop but also a place for recreation, socializing, or just for a walk alone. The progress of technology and human culture is changing. It's one of the factors that influence the impact of the decline in visitors at the old shopping center, every year such as a Pasar Baru shopping center. Re-Imagine Pasar Baru is a project that aims as a motor/propeller for Pasar Baru Community. Inviting the local people and Shop Owners to take part in making a change. Through a new program that strengthens unity and diversity to bring the conciseness cooperation (Gotong-royong) attitude that has been lost with the development of the times. Creating a place where people can socialize and interact, get closer, get to know each other, and also as a means of recreation for residents, visitors, shop owners, and also this project hopes to bring the Pasar Baru shopping area to life. Through the Urban Acupuncture method by analyzing the needs, potentials, deficiencies, demographics, ecology, etc. that characterize the Pasar Baru area. Where it can present a new program, and produce small-scale changes, but social catalytic intervention into the urban spatial structure. In physical and social-culture in PasarBaru.
\end{abstract}

Keywords: Community; Gotong Royong; Pasar Baru; Recreation; Urban Acupuncture 


\section{PENDAHULUAN Latar Belakang}

Kelurahan Pasar Baru kecamatan Sawah Besar, Jakarta Pusat merupakan salah satu distrik perbelanjaan tertua di Jakarta pusat. Yang dulunya menjadi pusat pemerintahan serta perdagangan Batavia pada Abad ke - 19. Menjadikan Kawasan Pasar Baru menjadi tempat yang memiliki nilai historis yang tinggi. Pasar Baru didirikan pada tahun 1820 dan masih bernama Passer Baroe dimana nama kota Jakarta masih Batavia. Disana merupakan tempat perbelanjaan bagi para orang-orang belanda yang tinggal di seberang Pasar Baru tepatnya di Jalan Veteran. Pembangunan toko-toko di Pasar Baru dibangun dengan gaya arsitektur China dan Europe. Kebanyakan toko-toko di kawasan Pasar Baru didominasi dengan toko pakaian, tekstil, sepatu, tailor, kacamata, olahraga dan perhiasan emas. Di masa kini, Pasar Baru juga dikenal akan keberagamannya yang tinggi dengan banyaknya warga keturunan Chinese, India, Pakistan, hingga Arab yang tinggal dan beraktivitas di kawasan tersebut. Serta kawasan ini juga dikenal dengan pusat wisata kuliner dan religinya. Beberapa toko-toko lama yang masih ada hingga kini adalah apotek Kimia Farma, toko Lee le Seng, toko perabot rumah tangga Melati, Tetapi seiring dengan berkembangnya zaman dan teknologi membuat pusat perbelanjaan ini kalah saing dengan mall- mall besar. Sekarang sebagian dari Pasar Baru mati/sepi pengunjung, citra kawasan tersebut secara perlahan- lahan pun menghilang.

Seiring berkembangnya zaman pusat perbelanjaan lama seperti Pasar baru mengalami penurunan pengunjung setiap tahunnya. Dimana mereka kalah saing dengan mall - mall baru dengan berbagai fasilitas dan teknologi serta keberagaman produk yang bisa ditemui disana. Ditambah munculnya Platform Online shopping menambah pesaing baru dengan metode perbelanjaan yang tidak mengharuskan pengunjung berbelanja di tempat perbelanjaan. Penurunan yang dialami Berdampak kepada penjualan toko-toko serta tingkat kepedulian masyarakat Pasar Baru, yang kurang memerhatikan dan juga merawat fasilitas sekitar. Tumbuhnya sikap individualis antara pedagang pun muncul. Sikap individualis muncul di era modern sekarang, salah satunya berkat bantuan teknologi. Mengakibatkan manusia secara tidak sadar Membuat suatu dinding maya yang menjadi sebuah batasan/Boundary. Aspek keberagaman produk dagangan, dan kurang terawatnya fasilitas, sarana, dan Prasarana merupakan penyebab penurunan pengunjung dan masyarakat lokal yang mengunjungi Pasar Baru.

\section{Rumusan Permasalahan}

Berdasarkan identifikasi masalah diatas, maka dapat dirumuskan beberapa masalah utama yang menjadi fokus penelitian pada proyek ini, yaitu:

a. Bagaimana merancang ruang ke- 3 serta pemilihan program baru dalam proyek, yang menghargai keberadaan nilai lokalitas, sejarah, dan budaya Pasar Baru?

b. Bagaimana membangun kembali nilai gotong-royong yang hilang di kawasan pusat perbelanjaan Pasar Baru sekarang?

\section{Tujuan}

Setiap proyek yang terbangun pasti memiliki maksud dan tujuan, adapun maksud dari ReImagine Pasar Baru recreation and community space ini antara lain:

a. Menghidupkan dan mengembailkan citra daerah Pasar Baru.

b. Menjadi motor atau pengerak perubahan terhadap masyarakat serta pengunjung Pasar Baru.

c. Menghadirkan kegiatan/aktivitas rekreasi baru ke dalam Pasar Baru.

d. Mendekatkan kesenjangan antar warga, menciptakan nilai gotong-royong yang hilang.

e. Membangun nilai kebersamaan dan kekompakan antar warga.

f. Menjadi wadah/tempat bersosialisasi dan interaksi warga sekitar.

g. Meningkatkan perekonomian Kawasan Pasar Baru. 


\section{KAJIAN LITERATUR}

\section{Third Place}

Menurut Ray Oldenburg (1989) Third Place / Ruang ke - 3 merupakan tempat netral dan tempat alternatif untuk semua golongan masyarakat yang bersifat publik dimana mereka dapat melakukan berbagai macam aktivitas berkelompok maupun individu dan mendorong interaksi antara masyarakat lainnya. Dan dapat digunakan oleh siapa pun. Third Place bagi setiap orang berbeda, bentuknya beragam sesuai dengan kehidupan dan budaya masyarakat sekitar.

Ruang ke- 3 dapat ditentukan dengan berbagai macam cara mulai dari hobi, kebiasaan, aktivitas, pekerjaan, kawasan ataupun keperluan seorang individu tersebut. Yang pada dasarnya masyarakat menghabiskan sedikit waktu di dalam ruang ke 3 tersebut di luar dari ruang 1 (home) dan Ruang 2 (Work Place).

a. Neutral ground: semua dapat mengunjungi tanpa adanya halangan/ Batasan

b. Leveler (a leveling place): Semua bisa masuk tidak terikat dengan status sosial, ekonomi, fisik dll

c. Conversation is the main activity: Aktivitas utamanya adalah berinteraksi, pertukaran informasi

d. Accessibility and accommodation: keterbukaan dari segi pencapaian / akses bagi semua orang

e. The regulars: Mempunyai pengunjung tetap, yang membentuk suatu ciri khas tempat tersebut.

f. A low profile: Tidak mahal, sederhana, ramah, terkesan seperti rumah

g. The mood is playful: Memiliki suasana yang segar danmenyenangkan

h. A home away from home: memiliki keterkaitan secara spiritual terhadap tempatini

\section{Urban Acupuncture}

Menurut Jamie Lerner (2003) Akupunktur perkotaan dalam teori sosio-lingkungan yang menggabungkan desain perkotaan kontemporer dengan akupunktur tradisional Tiongkok, menggunakan intervensi skala kecil untuk mengubah konteks perkotaan yang lebih besar. Situs dipilih melalui analisis agregat sosial, ekonomi dan faktor ekologi, dan dikembangkan melalui dialog antara desainer dan masyarakat. Sama seperti praktik akupunktur yang bertujuan menghilangkan stres dalam tubuh manusia, tujuan akupunktur perkotaan adalah untuk menghilangkan stres di lingkungan buatan. Di Taipei, ada bengkel akupunktur perkotaan yang bertujuan untuk "menghasilkan skala kecil tetapi intervensi katalitik sosial" ke dalam tata kota. dengan menganalisa beberapa lokasi di sekitar jalan Pasar Baru secara mikro lewat aktivitas serta kegiatan dan karakteristik dari lingkungan/ tempat tersebut.

\section{Three Theories Of Urban Spatial Design}

Menurut Roger Trancik (1986) Urban Spatial Design terdapat 3 elemen dalam merancang suatu ruang publik di suatu Kawasan yaitu massa dan ruang (figure), jejalur atau keterhubungan (linkage), dan tempat (place). Kualitas sebuah ruang publik dipengaruhi oleh bentuk dan tatanan ruang, dan juga harus dapat dicapai dengan mudah melalui jaringan infrastruktur yang jika dirancang dengan benar akan menghasilkan ruang berkegiatan yang tak hanya nyaman, tetapi juga membentuk perilaku positif bagi manusia di dalamnya. Selain itu, konteks budaya, sejarah, dan ekologi juga perlu diperhatikan dengan menyatukan bentuk, detail, ornamen yang unik sesuai nilai sosial, budaya dan persepsi visual; sehingga menghasilkan ruang publik yang memiliki karakteristik lokal. 


\section{Gotong Royong}

Gotong Royong merupakan salah satu ciri khas bangsa Indonesia khususnya Bulukumba, sebagaimana yang tertuang dalam pancasila yaitu sila ke 3 "persatuan Indonesia". Perilaku gotong royong yang dimiliki bangsa Indonesia sejak dahulu kala. Gotong royong merupakan kepribadian bangsa dan merupakan budaya yang telah berakar kuat dalam kehidupan masyarakat. Gotong royong adalah suatu kegiatan yang dilakukan secara bersama-sama dan bersifat suka rela agar kegiatan yang dikerjakan dapat berjalan dengan lancar, mudah dan ringan. Contoh kegiatan yang dapat dilakukan secara bergotong royong antara lain pembangunan fasilitas umum dan membersihkan lingkungan sekitar.

Menurut Sakjoyo dan Pujiwati Sakjoyo (dalam Selvi S. Padeo, 2012: 88) mengemukakan gotong royong merupakan adat istiadat tolong menolong antara warga dalam berbagai macam lapangan aktivitas sosial, baik berdasarkan hubungan tetangga kekerabatan yang berdasarkan efisien yang sifatnya praktis dan ada pula aktifitas kerja sama yang lain. Faktor Pendorong Gotong Royong:

a. Manusia sebagai makhluk sosial.

b. Keikhlasan berpartisipasi dan kebersamaan/persatuan.

c. Adanya kesadaran saling membantu dan mengutamakan kepentingan bersama/umum.

d. Peningkatan/pemenuhan kesejahteraan.

e. Usaha penyesuaian dan integrasi/penyatuan kepentingan sendiri dengan Bersama.

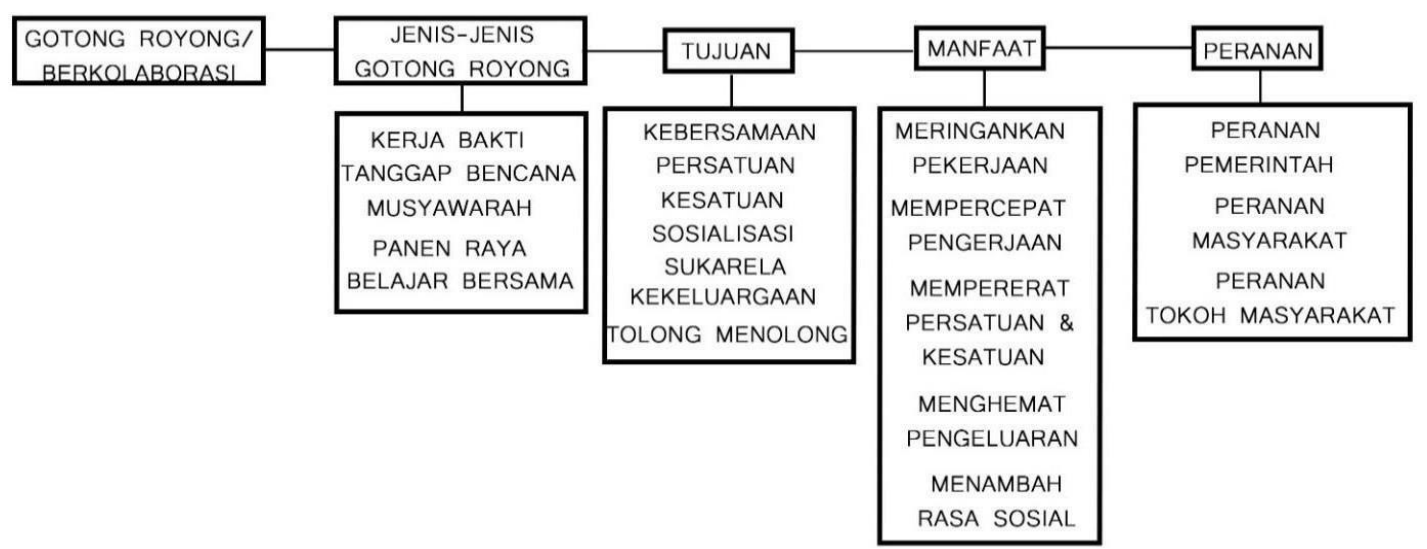

Gambar 1. Skema Pemikiran Pembentukan rasa gotong-royong Sumber: Penulis, 2020

\section{Shopping Street}

Menurut Collins Dictionary (25/2/2020) Shopping street merupakan area pejalan kaki yang berisi toko, restoran, dll. Membentuk satu unit arsitektur dan biasanya menyediakan fasilitas parkir mobil di sepanjang atau di suatu area perbelanjaan. Shopping street juga sama dengan pasar ruang luar seperti yang secara tradisional diadakan di alun-alun pasar atau di kota. Umumnya mereka berada di dekat pusat perkotaan yang bisa diakses semua orang. 


\section{Rekreasi}

Menurut KBBI, Rekreasi (25/2/2020)(Bahasa latin, re-creare) secara harafiah berarti 'membuat ulang', adalah kegiatan yang dilakukan untuk penyegaran kembali jasmani dan rohani seseorang. Hal ini adalah sebuah aktivitas yang dilakukan seseorang di samping bekerja Kegiatan yang umum dilakukan untuk rekreasi adalah parawisata, olahraga, bermain, dan hobi. Kegiatan rekreasi umumnya dilakukan pada akhir pekan.

\section{Komunitas}

Menurut Wikipedia, Komunitas (25/2/2020) adalah sebuah kelompok sosial dari beberapa organisme yang berbagi lingkungan, umumnya memiliki ketertarikan dan habitat yang sama. Dalam komunitas manusia, individu-individu di dalamnya dapat memiliki maksud, kepercayaan, sumber daya, preferensi, kebutuhan, risiko, kegemaran dan sejumlah kondisi lain yang serupa. Komunitas berasal dari Bahasa latin communitas yang berarti "kesamaan", kemudian dapat diturunkan dari communis yang berarti "sama, publik, dibagi oleh semua atau banyak".

\section{METODE PENJELASAN METODE}

Metode yang dilakukan penulis dalam melakukan perancangan adalah metode deskriptif dengan memaparkan atau mengidentifikasi data-data yang diperoleh serta melakukan komparasi dengan studi literatur yang mendukung teori untuk memperoleh program dasar serta peluang kombinasi dari program tersebut. Data yang dikumpulkan dalam studi laporan perancangan adalah data primer dan sekunder dimana, kegiatan pengumpulan data menggunakan metode sebagai berikut:

\section{Urban Akupuntur}

Metode yang dilakukan penulis merupakan metode urban akupuntur, dimana penulis menganalisis berbagai macam kondisi dan karakteristik dari kelurahan Pasar Baru. Dalam hal ini bersangkutan kepada aspek biologis, sosial, budaya, ekonomi, kegiatan, waktu, kebiasaan, dan aspek pembentuk tatanan kota lainnya. Penulis menganalisis berbagai titik lokasi di sepanjang jalan pusat Perbelanjaan dan kelurahan Pasar Baru. Guna untuk mengetahui segala macam bentuk kegiatan, aktivitas, karateristik, dan juga kategori pengguna ruang di lokasi tersebut Secara lebih mendetail. Bagaimana letak perbedaan secara desain ruangan setiap lokasi dan elemen pembentuk ruang tersebut. Penulis pun melakukan berbagai macam pengumpulan data dengan melakukan penyebaran kusioner, wawancara, dokumentasi video dan foto. Dan nantinya data tersebut dapat membantu penulis menentukan program baru serta desain arsitektur yang menjadi kriteria ruang ke-3 dan juga menghidupkan dan mengembalikan citra Kawasan Pasar Baru.

\section{Observasi}

Pengamatan langsung terhadap kondisi lokasi area perencanaan yang berada di kawasan pusat perbelanjaan Pasar Baru, Jakarta Pusat. Obeservasi Pengumpulan data primer meliputi :

a. kondisi existing yang berada di sekitar tapak perencanaan, yang menjadikan hal tersebut pertimbangan ke dalam perancangan bangunan baik secara langsung maupun tidak langsung.

b. Pengumpulan data berupa foto dan video suasana lingkungan sekitartapak.

c. Mengamati berbagai macam pola aktivitas/kegiatan, karakteristik lingkungan dan pergerakan manusia yang terjadi.

\section{Dokumentasi}

Teknik ini digunakan untuk mendapatkan data sekunder yang dikumpulkan melalui penelusuran pustaka dari berbagai instansi terkait, seperti pemerintah (pemerintah pusat maupun pemerintah kota) instansi pemerintahan, insatansi lainya yang berhubungan dengan 
proses perancangan, artikel atau makalah serta sumber-sumber lain yang berhubungan dengan perancangan ini.

\section{Wawancara}

Data yang dikumpulkan berasal dari pendapat responden atau informan tentang banyak hal yang bermanfaat bagi perancangan lebih jauh dan dapat dilakukan berkali-kali sesuai dengan keperluan peneliti tentang kejelasan masalah yang dijelajahinya.

\section{DISKUSI DAN HASIL ANALISIS LOKASI KAWASAN}
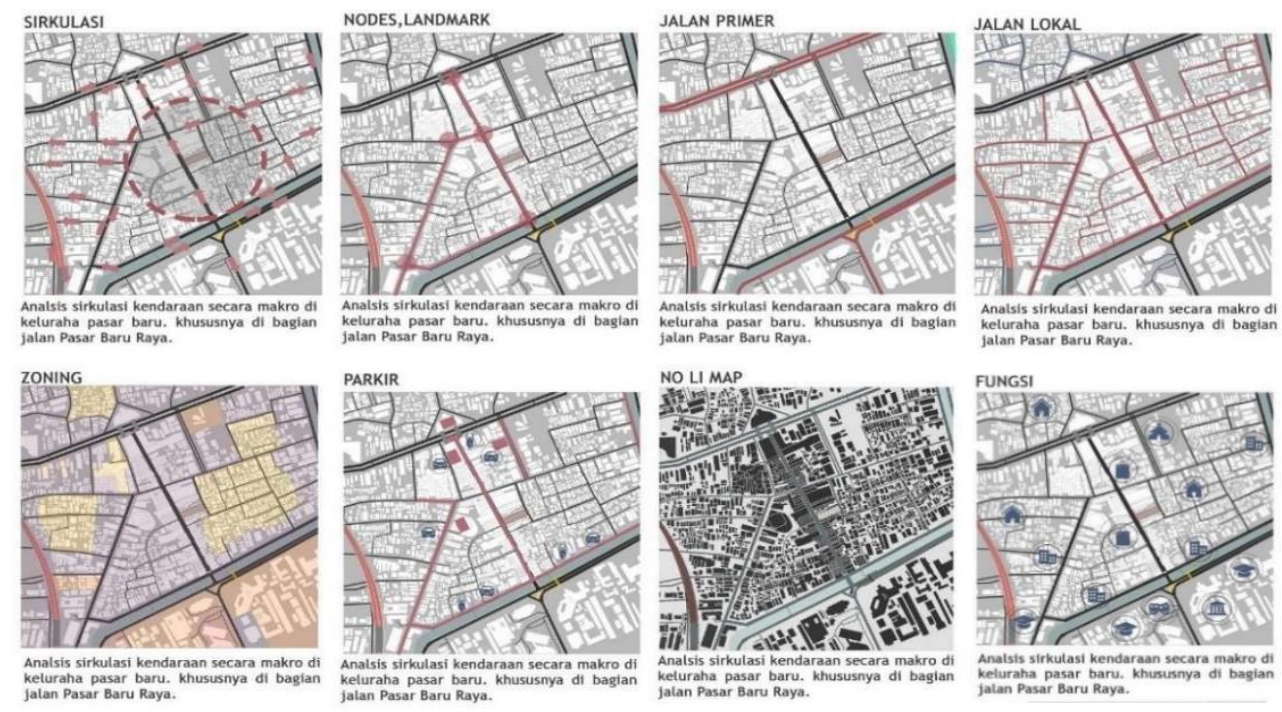

Gambar 2. Analisis Kawasan Makro Kelurahan Pasar Baru Sumber: https://Google.com/Maps/ kelurahan_Pasar Baru_Jakarta Pusat/Penulis/2020

Kawasan rancangan terletak di kelurahan Pasar Baru, Jakarta Pusat, terletak di tengah kota jakarta.Berbagai rangkaian Analisis yang dilakukan di kawasan Pasar Baru, guna untuk mengetahui karateristik kawasan, serta kelebihan dan kekurangan yang dapat membantu proses perancangan bangunan serta pemilihan fungsi / kegiatan dalam proyek.zoning Pasar Baru sendiri terbagi menjadi 3 zona, yaitu zona $30 \%$ pemerintahan, 60 \%komersil, dan 10 \%hunian. Berbagai macam fasilitas pendukung seperti transportasi umum dan juga fasilitas parkir juga tersebar di Kawasan Pasar Baru. Kawasan Pasar Baru ramai di pagi hingga sore hari dan hampir tidak ada kegiatan apa pun dimalam hari. Analisis nodes, landmark, kemacetan, sirkulasi dan lain-lain merupakan langkah awal yang dilakukan setelah melalukan observasi langsung di Kawasan Pasar baru.

\section{Data Demografi Kawasan}

Pengumpulan data - data demografi kependudukan, mata pencaharian, tipologi bangunan hunian, jumlah fasilitas kesehatan, sekolah, tempat ibadah, tempat perbelanjaan hingga keamanan pasar baru bisa dibilang cukup memadai . Kawasan ini didominasi oleh kaum pelajar dan pekerja khususnya di daerah Perbelanjaan Pasar Baru.data-data tersebut sebagian diperoleh dari observasi langsung serta wawancara di lapnagan dan pada akhirnya Penentuan data-data ini dapat membantu penulis dalam memahami Kawasan, kebutuhan serta, kebiasaan masyarakat Pasar Baru. 

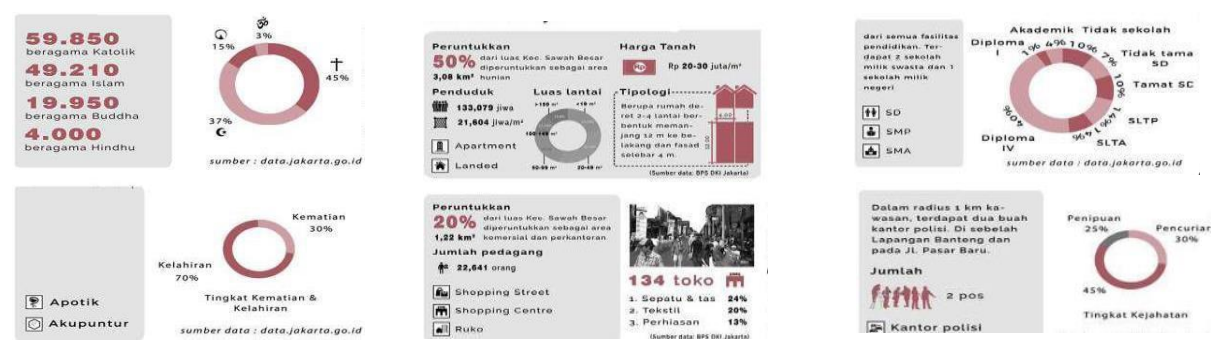

Gambar 3. Demografi kependudukan Pasar Baru

Sumber: https://jakpuskota.bps.go.id/publication/2019/08/16/kota-jakarta-pusat-dalam-angka2020.html

Berikut pemetaan fasilitas serta bangunan iconic yang berada di kawasan pasar baru:

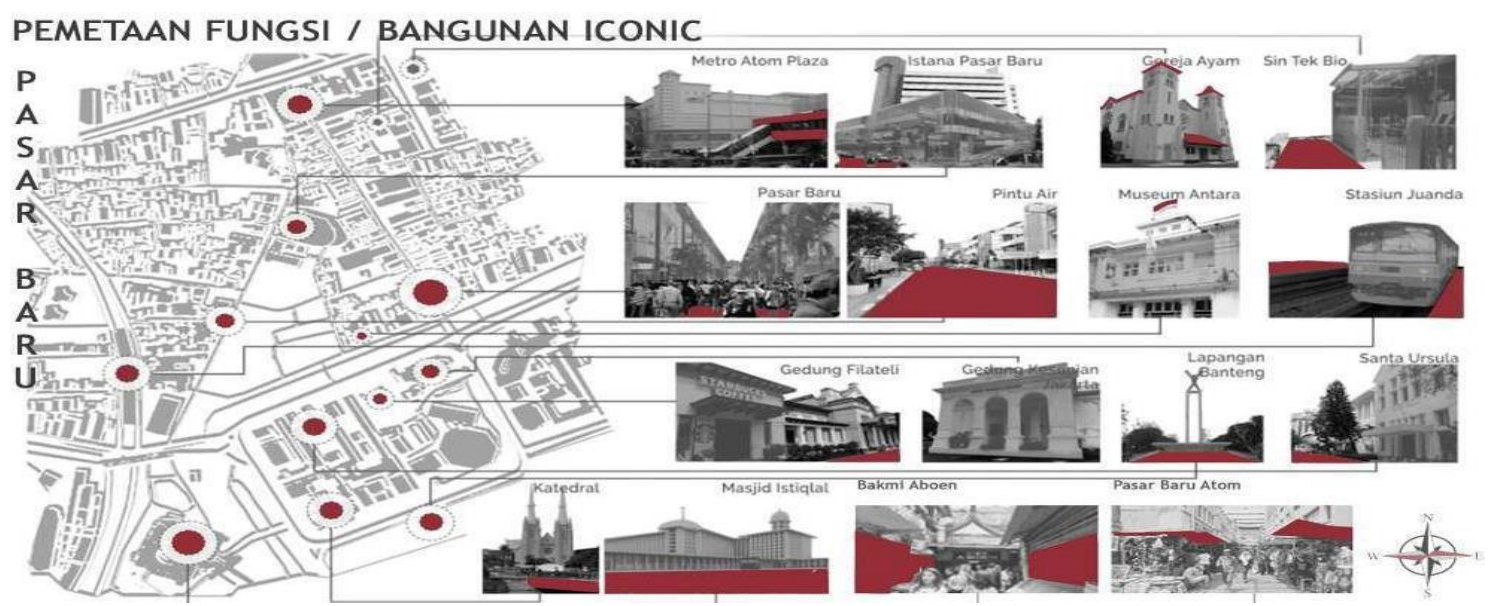

Gambar 4. Pemetaan Fasilitas dan Bangunan Iconic di Kawasan Pasar Baru

Sumber: https://Google.com/maps/place/Pasarbaru dan diedit olehpenulis/2020

\section{Lokasi Tapak}
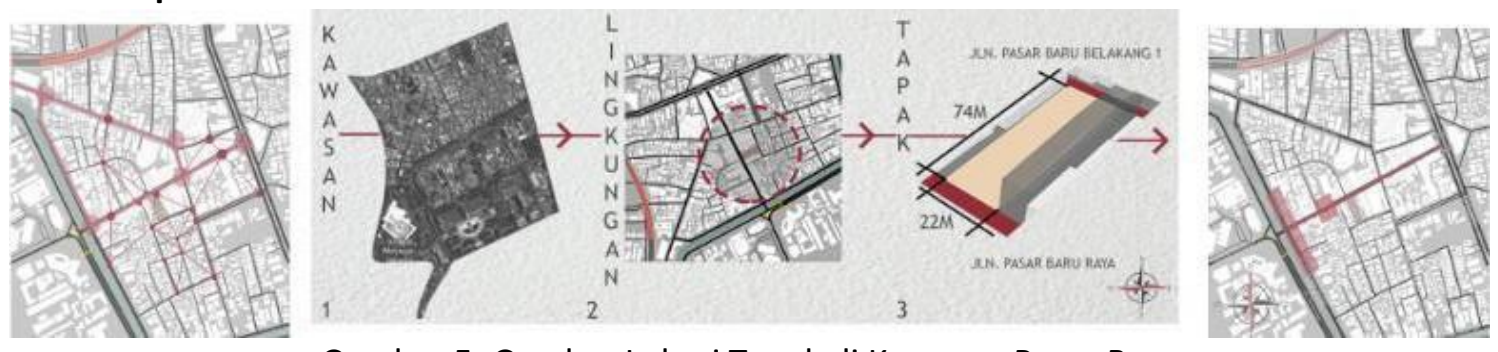

Gambar 5 .Gambar Lokasi Tapak di Kawasan Pasar Baru

Sumber: https://Google.com/maps/place/Pasarbaru dan diedit oleh penulis/2020

Lokasi tapak berada di jalan Pasar Baru Raya tepatnya berada di dalam distrik perbelanjaan kawasan pasar baru. tapak memiliki ukuran $22 \times 74 \mathrm{~m}$ dengan luas tanah sebesar $1.628 \mathrm{~m}^{2}$. Tapak juga berada di kedua distrik komersil dan hunian. Dimana terdapat 2 aktivitas dan kegiatan yang sangat berbeda di setiap entrance atau akses masuk ke dalam tapak. 


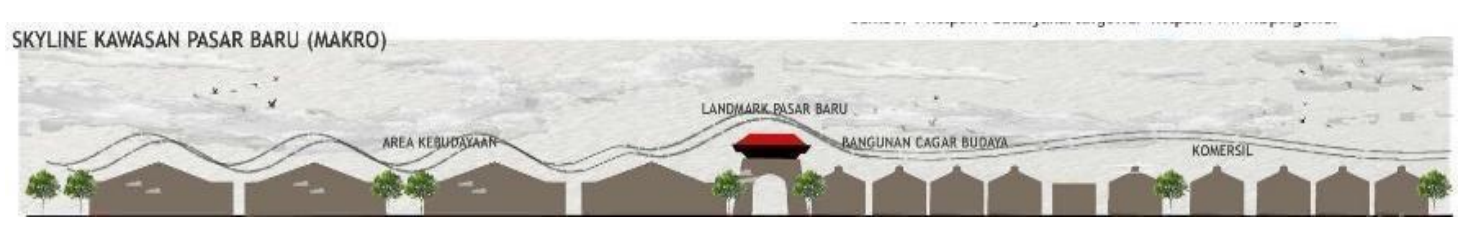

Gambar 6 . Skyline Kawasan Pasar Baru

Sumber: Penulis, 2020

\section{Potensi dan Kekurangan Tapak}

Kawasan serta tapak yang dipilih memiliki beberapa potensi dan kekurangan sebagai berikut: Potensi: tapak berada di Kawasan pusat perbelanjaan pasar baru, ramai dikunjungi oleh pengunjung, memiliki nilai lokalitas, sejarah, dan budaya yang ikonik. Terletak di pusat kota jakarta dan jaringan transportasi Kawasan sudah terhubung dengan cukup baik.

Kekurangan: ketentuan dan peraturan bangunan, berserta jalan dan fasilitas umum yang rusak di kawasan pasar baru. Mengalami penurunan pengunjung, serta jumlah sisi fasade bangunan yang bisa dirancang sedikit. Berikut penjabaran peraturan pembangunan di proyek tapak: Kecamatan : Sawah Besar / Kelurahan: Pasar Baru / kode blok : 10 / Sub Zona : K2 / KDB : 75 / KLB: 3 KB : 4 / KDH : 30 / KTB : 55 / Tipe : D / Kegiatan : Perkantoran / Zonasi : ungu.

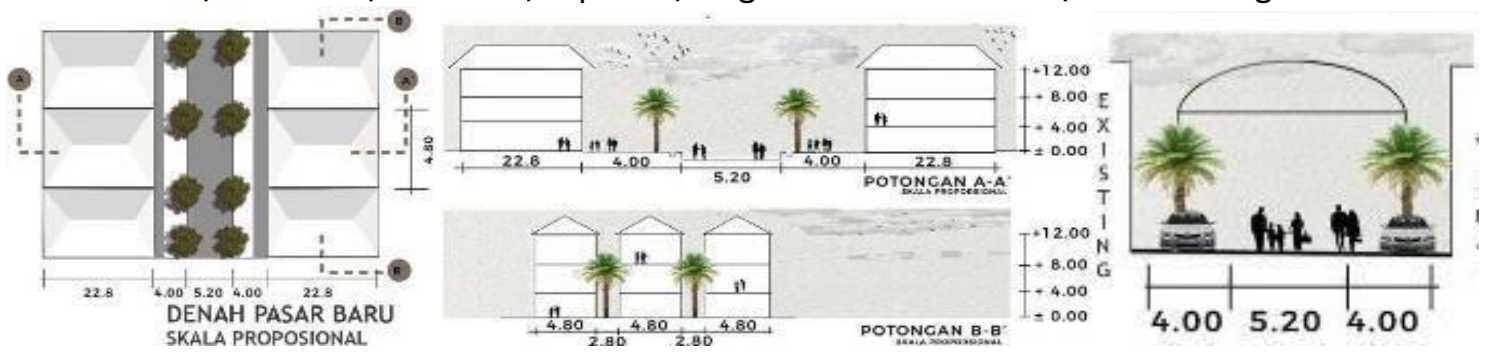

Gambar 7 .Denah dan Potongan Kawasan perbelanjaan Pasar Baru Sumber: Penulis, 2020

\section{Skema Berpikir dan Program Kegiatan}

Bedasarkan analisis yang dilakukan muncul suatu program kegiatan baru yang masuk di dalam proyek. Program tersebut termasuk ke dalam kriteria edutainment.

Program tersebut dipilih bedasarkan kebutuhan serta aspirasi masyarakat sekitar akan kebutuhan ruang sosial bersama yang dapat menjadi tempat singgah dan memenuhi fasilitas rekreasi bagi warga lokal. Disamping itu program juga dibagi menjadi kegiatan untuk masyarakat distrik hunian dan distrik perbelanjaan. Menyesuaikan dengan program / fungsi yang sudah ada di kawasan tersebut. 


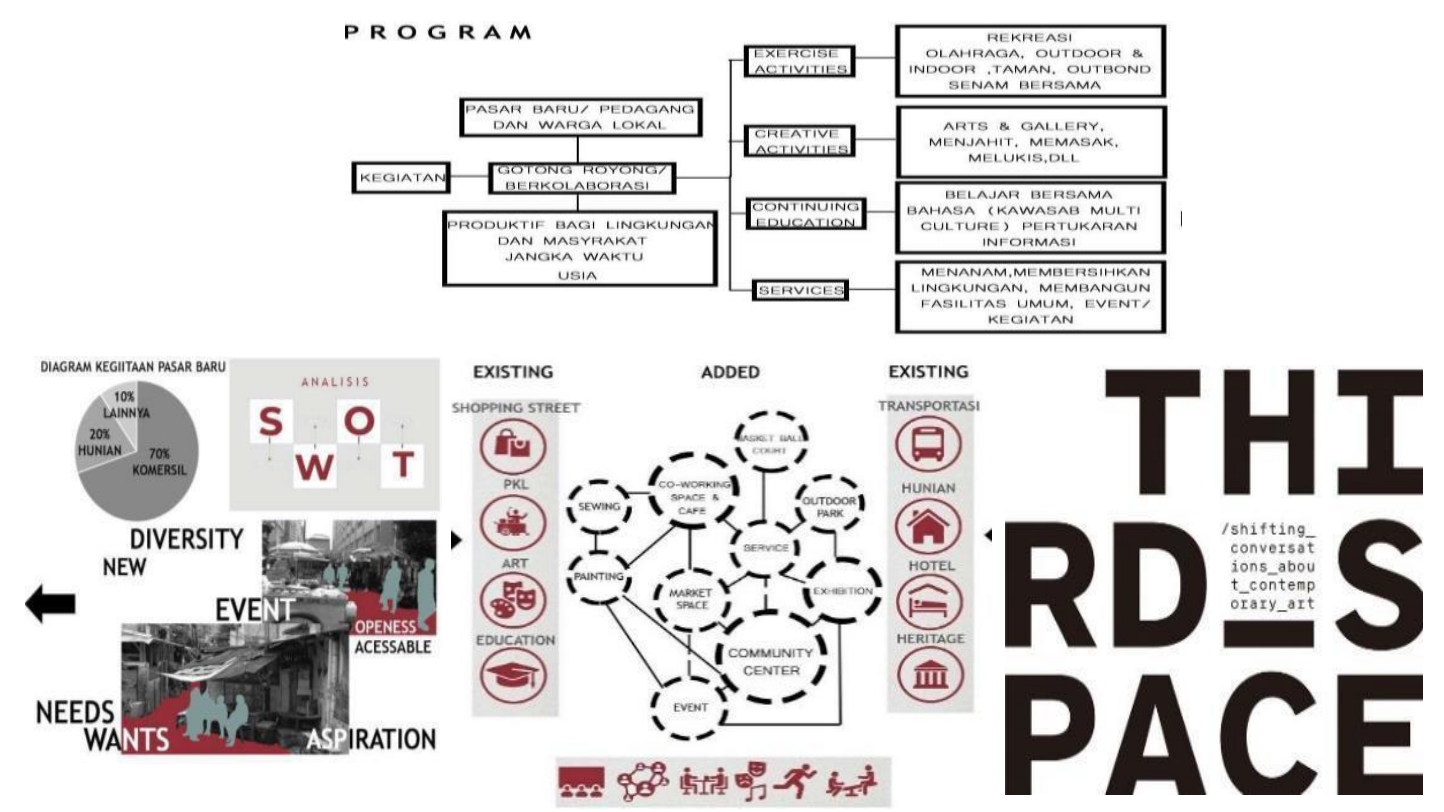

Gambar 8. Skema Berpikir dan Skema Program Kegiatan Sumber: Penulis, 2020

\section{Proses Transformasi Massa Bangunan}

Bedasarkan Analisis yang dilakukan berserta teori-teori, data, analisis makro dan mikro, program kegiatan, metode perancangan (urban acupuncture) yang sudah dilakukan. Kemudian masuklah penulis pada tahap Perancangan desain massa bangunan. Yang mengacu kepada konsep keterbukaan dan hubungan dengan lingkungan dan bangunan sekitar tapak.
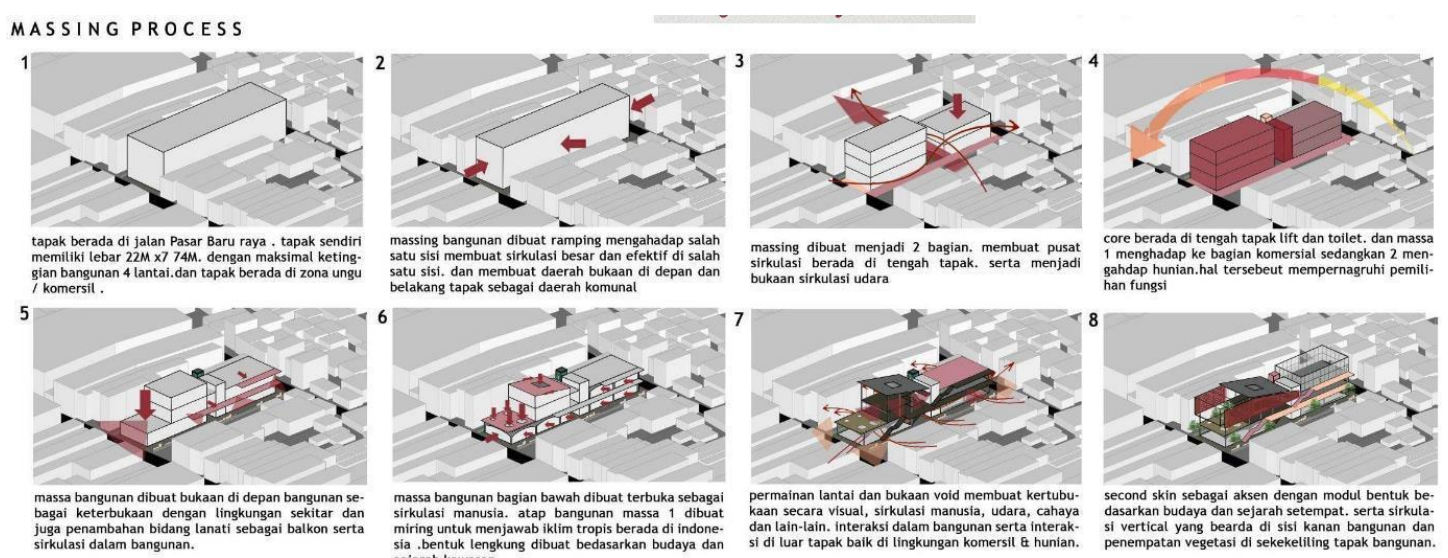

Gambar 9. Tahap-tahap Perancangan Massing Bangunan

Sumber: Penulis, 2020

\section{Hasil}

Re-imagine Pasar Baru mengajak Pembaca untuk memandang sisi lain dari Pasar Baru bedasarkan potensi serta peluang Pasar Baru dari segi keunikan budaya, sejarah, serta konsep yang ada. Proyek bertujuan sebagai motor / pengerak kawasan perbelajaan Pasar Baru lewat injeksi program-program baru dibidang edutainment guna membangun daya saing dengan mall-mall besar lainnya dari segi keberagaman produk dan fungsi, dengan tujuan menghidupkan kembali kawasan tersebut.

Menyediakan Third place bagi pengunjung, pedagang, masyarakat hunian Pasar Baru. 
Membangun nilai kekompakan, serta mengatasi kebosanan lewat wadah rekreasi dan komunitas untuk masyarakat Pasar Baru.

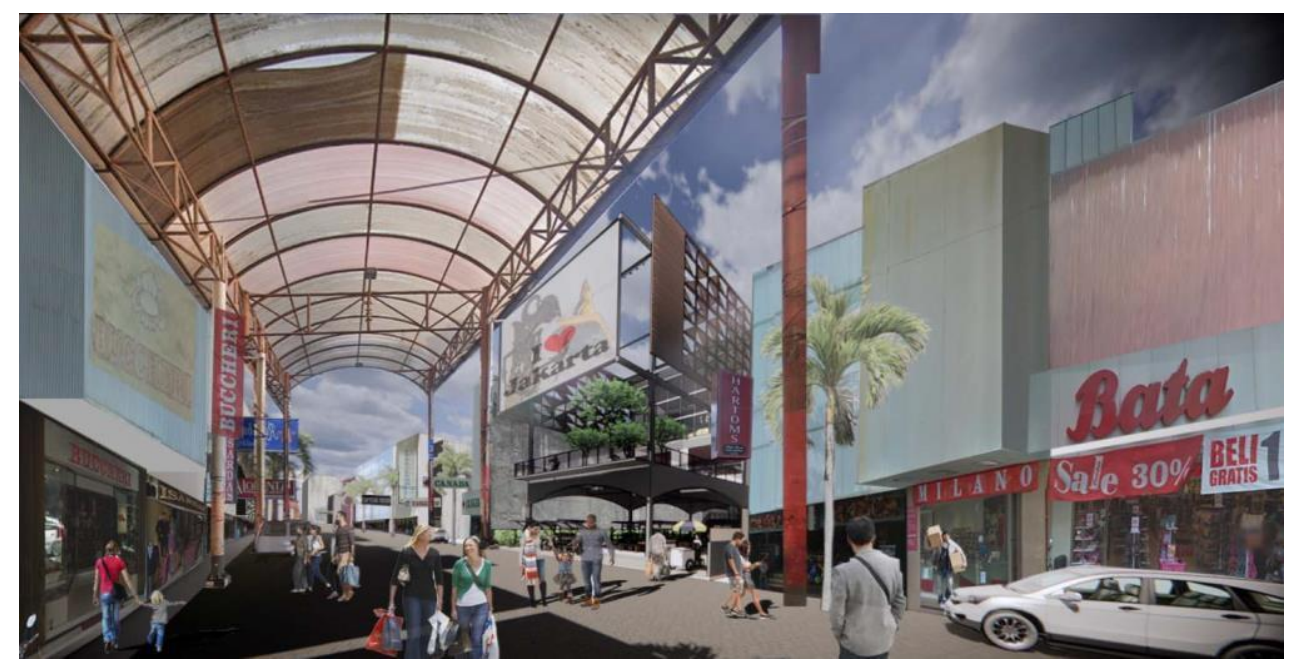

Gambar 10. Perspektif Exterior Bangunan Kawasan Pasar Baru

Sumber: Penulis, 2020

\section{Ruang Komunal Pasar Baru}

Pasar Baru merupakan tempat perbelanjaan yang mengambil konsep street shopping dengan aktivitas utama yang dilakukan di jalan utama Jalan Pasar Baru Raya, mulai dari aktivitas berjalan kaki, kendaraan bermotor hingga parkiran. Untuk itu proyek mengusulkan suatu ruang terbuka dimana masyarakat dapat berkumpul setelah berbelanja atau mengunjungi Pasar Baru. dimana mereka bisa santai berbincang serta istirahat di tengah melakukan aktivitas berbelanja.

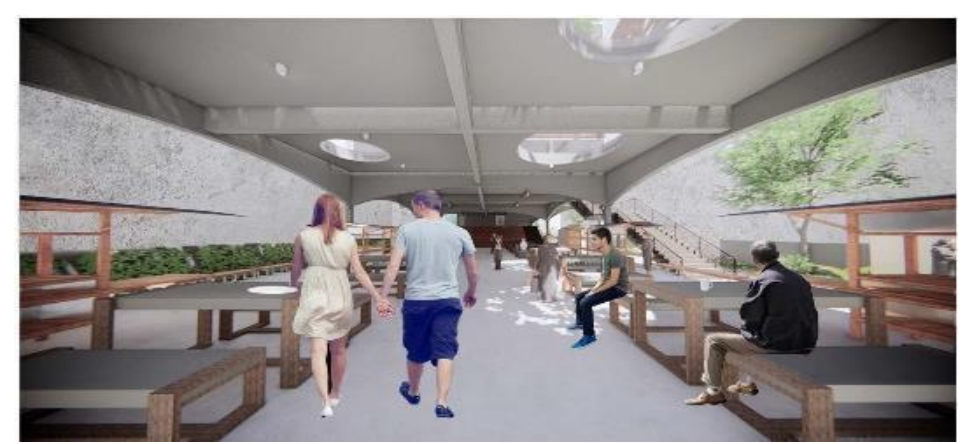

Gambar 11. Food, Performance, and Socializing Area Sumber: Penulis, 2020

Area komunal yang terbentuk, dibagi menjadi 2 yaitu untuk komersil dan untuk hunian sekitar. Desain serta fungsi dibedakan dengan aktivitas berbeda yang ada disana. Area komunal daerah komersil merupakan ruangan multi fungsi yang memiliki berberapa aktivitas di dalamnya seperti menjadi tempat makan dan berinteraksi satu sama lain dan juga menjadi spot untuk pertunjukan musik dan event - event lainnya. Desain stand dan meja serta kursi yang bersifat portable dan dapat dipindahkan memberikan satu ruangan yang besar untuk pertunjukan. Disamping itu juga dilengkapi oleh amphitheatre yang berguna sebagai area penonton saat pertunjukan dan juga menjadi arah sirkulasi vertikal ke lantai 2. 


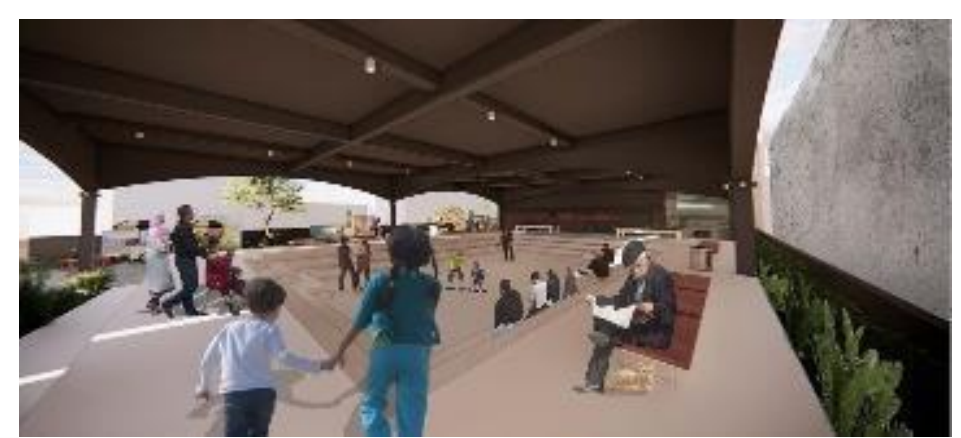

Gambar 12. Community and Playing Area

Sumber: Penulis, 2020

Daerah hunian dirancang dengan desain sederhana dimana menjadi tempat masyarakat hunian Pasar Baru dapat melakukan aktivitas sehari -hari seperti bermain, duduk dan berbincang, olahraga dan masih banyak lagi. Elemen desain memperhatikan pengguna ruangan dimana cukup banyak lansia dan anak-anak, sehingga pencapaian di desain menggunakan ram. Berbagai aktivitas seperti siskamling, serta acara kelurahan bisa diadakan di tempat ini. Fasilitas pendukung seperti playing area yang menghadirkan permainan tenis meja dan juga tempat parkir sepeda mengingat pencapaian entrance belakang merupakan bagian dari perumahan kawasan pasar baru. Kedua area komunal ini berusaha menciptakan suatu daerah komunal yang memiliki ke 7 aspek kriteria Third Place. (Ray Oldenbu)

\section{SELASAR SENI}

Accessibility dan juga connectivity dari segi pencapain terhadap bangunan serta lingkungan sekitar juga menjadi ide desain yang diterapkan. Dikarenakan melihat potensi tapak yang memanjang dan juga berada di dua sisi Jalan Pasar Baru Utama dan Pasar Baru Belakang 1. Selasar dibuat memanjang menghubungkan kedua jalan utama yang dapat dilalui di dalam proyek rancangan. Desain selasar dibuat dengan motif kain berbentuk bunga atau dedaunan yang menjadi salah satu motif yang berada di kain tekstil pasar baru. motif tersebut di desain dalam bentuk pot tanaman yang bertujuan untuk menghadirkan pengalaman ruang yang interaktif bukan hanya linear yang disebabkan oleh panjangnya selasar. Berbagai aktivitas tambahan seperti area jajanan di pinggir selasar, tempat duduk hingga kumpulan art work yang berasal dari seniman lokal yang menghiasi dinding sekitar tapak yang menghidupkan suasana ruang yang mengundang.

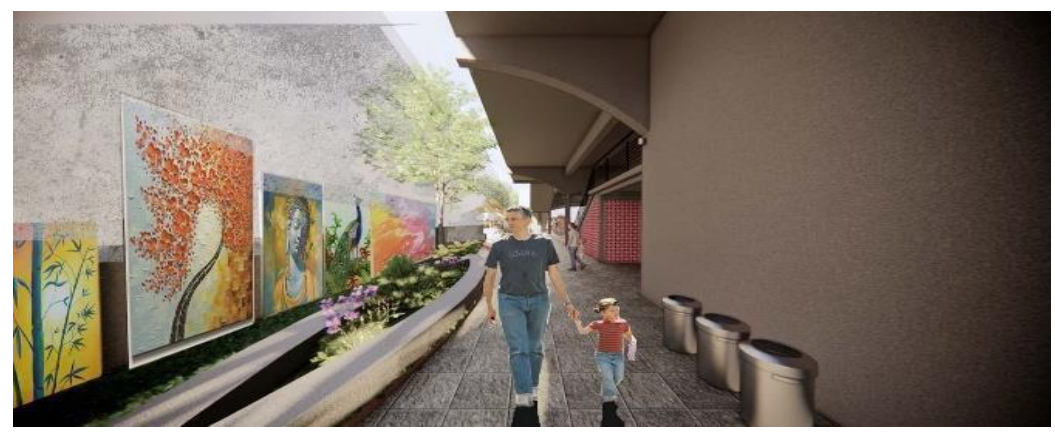

Gambar 13. Selasar seni

Sumber: Penulis, 2020

\section{Ruang Seni Edukatif Pasar Baru}

Disamping memiliki tekstil Pasar Baru juga terkenal dengan seni untuk itu Re-Imagine Pasar Baru menghadirkan fungsi Painting and Sewing Studio dimana pengunjung atau masyarakat Pasar Baru bisa datang dan belajar mengenai seni lukis dan menjahit lewat program yang diusul oleh masyarakat atau relawan pedagang Pasar Baru, Guna mempromosikan pusat 
perbelanjaan tersebut lewat media dan output yang interaktif dan produktif. terdapat pula co-working space serta coffee shop untuk pengunjung dan masyarakat lokal beraktivitas, meeting ataupun sejenak menikmati secangkir kopi.
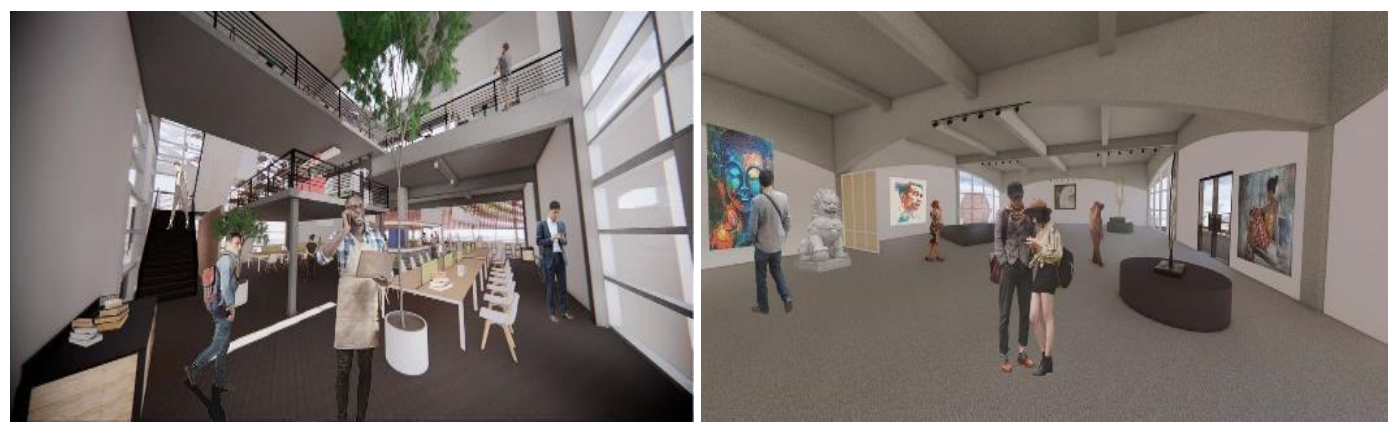

Gambar 14. R. Painting and Sewing Studio, R.Pameran dan R.Coworking Space

Sumber: Penulis, 2020

Terdapat juga ruang pameran, di seberang studio bertujuan sebagai r. serbaguna untuk acara pameran seni lukis, seminar dan acara indoor lainnya. Yang dapat dipergunakan oleh publik. Desain ruangan tersebut di desain dengan jendela di beberapa sisi ruangan sebagai bukaan pencahayaan alami masuk. Dan dinding pembatas partisi terbuat dari papan gypsum yang ringan dapat dipindahkan untuk membagi -bagi ruangan sesuai kebutuhan dan meciptakan ruangan yang adaptif. Sedangkan furniture studio di desain dengan membagi 2 bagian meja dengan pusat ditengah memudahkan sirkulasi dan pencapaian atau pun memperhatikan kursus yang sedang berlangsung di tengah ruangan. Terdapat mezanin di dalam ruangan sebagai ruang perantara menuju co-working space. Permainan void diberikan dari 3 level tersebut memberikan keterbukaan visual, pencahayaan serta pengudaaran di dalam ruang. Membuat 3 ruangan tersebut menjadi satu kesatuan yang utuh.

\section{Pasar Baru Olahraga}

Selain itu kegiatan lain yang tersedia untuk masyarakat Pasar Baru merupakan fasilitas rekreasi di bidang olahraga. Dimana tepat berada di sebelah bagian distrik hunian. Masyarakat dapat berkumpul dan melakukan aktivitas olahraga di pagi hari maupun di sore hari. Selain itu juga bisa menjadi tempat penyelengaraan berbagai macam acara seperti lomba 17 agustus kelurahan Pasar Baru. lapangan diletakan di lantai atas untuk memaksimalkan potensi lahan serta sinar matahari yang di dapat saat berolahraga. Untuk mendukung aspek keterbukaan pemilihan material pagar terbuat dari besi hollow stainless steel serta wire mesh digunakan mengingat iklim tropis dan curah hujan di Indonesia.

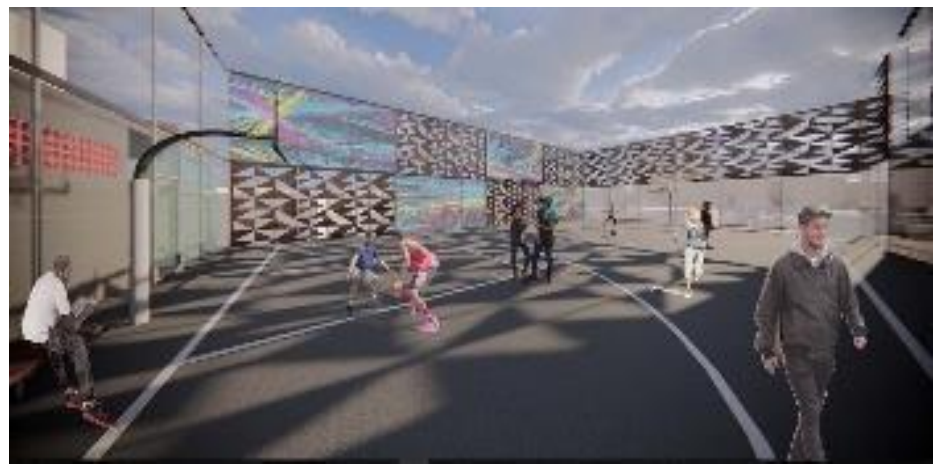

Gambar 15. Lapangan Basket Outdoor

Sumber: Penulis, 2020 


\section{KESIMPULAN DAN SARAN}

Re-Imagine Pasar Baru bertujuan menjadi Third Place di kawasan Pasar Baru. menyediakan suatu ruang interaksi, sosialisasi, dan rekreasi bersama bagi masyarakat lokal, pedagang, dll. Menyediakan kebutuhan dan aspirasi masyarakat lewat program baru dibidang Edutaiment. Urban akupuntur sebagai metode Pelepas stress yang berada di Kawasan tersebut dan juga memberikan warna baru ke dalam ruang kota. Mengisi program yang bertujuan untuk membangun rasa gotong-royong dan mengisi rasa kebosanan masyarakat Pasar Baru lewat keberagaman program. Yang nantinya diharapkan dapat menghidupkan dan mengembalikan kembali citra pusat perbelanjaan Pasar Baru dan Kawasan sekitar.

\section{REFERENSI}

Lerner, J.(2003). Urban Acupuncture celebrating pinpricks of change that enrich city lifes .washington.Island Press. Diakses dari https://islandpress.org/books/urbanacupuncture. pada tanggal 13 Maret 2020.

Oldenburg, R.(1989).The Great Good Place.usa.De copa Press. Diakses dari https://www.goodreads.com/book/show/4119.The_Great_Good_Place. pada tanggal 10 Febuari 2020.

Sakjoyo, Pujiwati, S. (2012). Selvi S.Padeo. Diakses 13 Maret 2020, dari https://www.pelajaran.co.id/2019/23/gotong- royong.html.

Trancik, R.(1986). Finding Lost Space: Theories Of Urban Spatial Design. New York: John Wiley \& Sons, Inc. Diakses dari https://www.slideshare.net/rohayah3/lecture-12-theories-ofurban-spatial-design/. (2020). Definisi dan Karakteristik Komunitas/community. Diunduh 25 Febuari 2020, dari https://id.wikipedia.org/wiki/Komunitas. (2020). Definisi dan Karakteristik shopping area dan street market. Diunduh 25 Februari 2020, dari https://www.collinsdictionary.com/dictionary/ english/shopping-area. (2020). Definisi dan karakteristik rekreasi/ Recreation. Diakses 26 Febuari 2020, dari https://kbbi.web.id/rekreasi. (2020). Diakses 10 Februari 2020, dari https://www.goodreads.com/book/show/4119.The_Great_Good_Place. 
